A BACKGROUND TO ENGINEERING DESIGN 
Other Macmillan titles of related interest

Introduction to Engineering Materials

V. B. John

Understanding Phase Diagrams

V. B. John

Analysis and Presentation of Experimental Results

R. H. Leaver and T. R. Thomas

Production Engineering Technology, Second Edition

J. D. Radford and D. B. Richardson

Mechanical Engineering Design, Second Edition

G. D. Redford 


\title{
A BACKGROUND TO \\ ENGINEERING DESIGN
}

\author{
PETER POLAK
}

Department of Mechanical Engineering,

University of Sheffield 


\begin{abstract}
All rights reserved. No part of this publication may be reproduced or transmitted, in any form

or by any means, without permission.
\end{abstract}

\author{
First published 1976 by \\ THE MACMILLAN PRESS LTD \\ London and Basingstoke \\ Associated companies in New York Dublin \\ Melbourne Johannesburg and Madras
}

ISBN 978-0-333-18771-5

SBN 333187717

ISBN 978-1-349-02707-1 (eBook)

DOI 10.1007/978-1-349-02707-1

Text set in 10/11 pt. IBM Press Roman, printed by Photolithography and bound in Great Britain at The Pitman Press, Bath

This book is sold subject to the standard conditions of the Net Book Agreement.

The paperback edition of this book is sold subject to the condition that it shall not, by way of trade or otherwise, be lent, re-sold, hired out, or otherwise circulated without the publisher's prior consent in any form of binding or cover other than that in which it is published and without a similar condition including this condition being imposed on the subsequent purchaser. 


\section{Contents}

Preface

1. Introduction and some Ergonomics

Outlines the scheme of thoughts which constitute the design of a machine or product; particular attention is given to ergonomic aspects.

2. Loads and Structures

Discusses the optimum shape of a structure in relation to the loads it has to bear.

3. How Strength can Fail

Goes into detailed considerations of strength, referring particularly to buckling and fatigue problems; lessons are drawn from some recent failures.

\section{Stable and Unstable Systems}

Describes inherent stability and some useful unstable systems; a control system is described qualitatively.

\section{Some Motions}

Refers to kinematics, linkages and cams as commonly used in engineering, particularly in vehicles.

\section{Materials in Outline}

Discusses materials in general terms and describes the properties of some widely used ones; attention is drawn to brittle fracture of steels and to corrosion.

\section{Static Joints}

Concentrates on welded, riveted and other static joints, with attention to static and fatigue strengths, permissible stress levels, discontinuity effects, kink plates, etc. 
8. Bearings and Seals

Deals mainly with rolling and sliding bearings (hydrodynamic and hydrostatic types) and fluid seals.

9. Damping, Mountings and Vibration

Discusses mountings, vibrations, damping, etc., and briefly refers to noise.

10. Some Points on Manufacture and Appearance

Considers design aspects of manufacturing methods, briefly describing some of the less familiar ones and concludes with a short section on visual design aspects.

Appendix

List of symbols; Twist-bend buckling; Unsymmetrical sections;

Behaviour of bolted joints; Bellows expansion joints; Some useful theorems.

Index 


\section{Preface}

'Design' is a popular expression with varying implications: wallpaper design differs from dress design, 'industrial design' differs from engineering design. Some journals go so far as to use the word design for the external aspects of a machine, calling the insides, a little airily, the 'engineering'; for example, a teleprinter was described as designed by a designer particularly well known for elegant tableware, the makers of the works were mentioned a long way further down in the 'credits'. Engineers in turn insist that the word should refer almost entirely to the works, or in simple cases to the stressing.

This semantic difference is best resolved by those engineers who themselves display a strong sense for the appearance of a product and are prepared to recognise that those trained mainly in the visual arts and relatively free from mechanical habits can have something refreshing to offer.

The present book is concerned almost entirely with functional aspects; indeed the author feels that not only in machinery should the externals generally take their place with all the other considerations; for instance in light-fittings, efficiency and styling can be at loggerheads. Only where the function is simple and sufficient strength easily provided, as in furniture, can external design take precedence. Occasionally the function and ease of making actually suggest a happy shape.

Engineering design at its most restricted is finding the right thickness for a part when shape, function, loading and material are pre-decided. As will be seen later, even this is not always easy. Higher levels of elaboration are reached in 'shoppinglist' design, finding the most economical and/or versatile process plant or production line consisting of standard but expensive items of equipment. The most creative design activity, starting from basics, is also the most demanding if it is not to consist of repeating old mistakes along with inventing a few new ones.

This book does not supersede any established manuals but brings together key points from the past and more recent data. The references include items dating back seventy years but the majority are only a few years old.

To avoid items like 'this is a bolt, this is a clamp, this is a keyway', familiarity with the names and uses of basic mechanical components is assumed, as is a knowledge of basic stress and strain relations appropriate to first- or second-year undergraduates in engineering.

To reduce tediousness, extensive explanations have been avoided; it is felt that the intended reader is better served by erring on the side of brevity, leaving room for thought yet, it is hoped, no room for misunderstanding.

Standard drawing conventions have been varied slightly in the interests of 
clarity; each figure should be considered independently. Generous use of shading, though unnecessary for many, should help to minimise uncertainties for those students who are unfamiliar with machinery details.

To avoid irritating brackets, SI units are used generally, though occasionally Imperial units are shown. For stresses, a convenient set of figures to relate the more common units together is the ultimate strength of a low-carbon steel, 28 tons/in. ${ }^{2} \approx 400 \mathrm{MN} / \mathrm{m}^{2} \approx 60000$ p.s.i. $\left(=1 \mathrm{bf} /\right.$ in. $^{2}$ ).

Apologies for digressions, approximations, simplification of facts and verbal short-cuts are tendered here and now, in bulk.

The author gratefully acknowledges his debt to all those who taught him or provided opportunities for learning and experience.

Thanks are due to Sheffield University for the help received from the Applied Science Library, the photographic section, the workshops and laboratories of the Mechanical Engineering Department and for a certain amount of clerical assistance; also to Sheffield City Library which was found to form a most useful complement to the University library. 